\title{
Fundamentos teóricos e jurídicos da profissão de enfermagem
}

\author{
Taka Oguisso ${ }^{1}$ \\ Maria José Schmidt ${ }^{2}$ \\ Genival Fernandes Freitas ${ }^{3}$
}

Este estudo tem como objetivo discutir e analisar a legislação de enfermagem, através de retrospectiva histórica até os dias atuais, em especial no exercício profissional. Ele pontua a necessidade de conhecer melhor a enfermagem e compreender

a importância da legislação, propiciando uma participação mais ativa do coletivo rumo ao desenvolvimento e ao reconhecimento social.

Descritores: Enfermagem; Exercício; Legislação profissional.

\section{Theoretical and juridical foundations of the nursing profession}

This paper aimed at discussing and analyzing the nursing legislation, through an historical retrospective until current days, especially within the field of the professional practice. It highlights a need to better know nursing and understand the importance of the legislation, therefore providing a more active participation of the collective nursing toward the profession development and social recognition.

Descriptors: Nursing; Practice; Professional legislation.

\section{Fundamentos teóricos y jurídicos de la profesión de enfermería}

Este estudio tiene como objetivo discutir y analizar la legislación de enfermería a través de una retrospectiva histórica hasta los días actuales, especialmente en el campo del ejercicio profesional. Se enfatiza la necesidad de conocer mejor la enfermería y comprender la importancia de la legislación, a fin de asegurar una participación más activa del colectivo de la enfermería rumbo al desarrollo y al reconocimiento social. Descriptores: Enfermería; Ejercicio; Legislación profesional.

\section{INTRODUÇÃO}

V iver em sociedade exige um complexo de normas disciplinadoras que facilitem o convívio entre os indivíduos que a compõem, pois todo comportamento humano está sujeito a regras criadas pelo homem, para manter o equilíbrio das relações sociais. Tais regras são denominadas leis que, em conjunto, formam a legislação. Em nível nacional, o conjunto dessas regras, denominado Direito Positivo, deve ser cumprido por todos, pois do contrário, sanções podem ser aplicadas para os que violarem preceitos.

Em nível internacional, órgãos como a Organização das Nações Unidas (ONU) ou a Organização Mundial da Saúde (OMS) entre outras, podem apenas proclamar como ocorreu no caso da Declaração Universal dos Direitos Humanos; ou os representantes das nações podem se propor e decidir, através de resoluções, a fazer alguma coisa que se comprometem a cumprir. Convenções internacionais precisam ser ratificadas por meio de leis nacionais, em cada país, para serem cumpridas. Outra forma de ação internacional é a recomendação, pois cada nação sendo soberana é livre para seguir ou não os ditames internacionais.

No Brasil, o exercício de qualquer trabalho, ofício ou profissão está regulamentado pela Constituição(1), desde que satisfeitas as qualificações estabelecidas em leis específicas. Denominamse profissões liberais as atividades desempenhadas com independência e autonomia a uma livre clientela, o que não exclui a possibilidade de ser o trabalhador liberal suscetível de um contrato de trabalho, em que se evidencie uma subordinação, regulada e protegida pelas leis trabalhistas. Assim, o caráter distintivo da profissão liberal está principalmente em ser uma profissão cujo exercício depende de conhecimentos acadêmicos específicos ou cujo êxito decorre da capacidade intelectual do profissional. 0 exercício da profissão liberal depende de um título de habilitação ou qualificação, como um diploma, expedido conforme uma lei.

Do ponto de vista jurídico, as profissões de livre exercício no país estão regulamentadas por leis. Isso deveria estimular os profissionais a se interessarem pelo estudo da legislação, pelo menos daquela que se relaciona com o exercício de sua profissão. A importância desse estudo se justifica pelos motivos abaixo.

O primeiro baseia-se no fato de que é por via da legislação que se criam ou se extinguem direitos e deveres. Do nascer ao morrer, as pessoas realizam atos jurídicos, mesmo sem tomar muita consciência disso. $\mathrm{O}$ segundo reside num pressuposto de que todo cidadão deve conhecer as leis de seu próprio país. $\mathrm{Na}$ Lei de Introdução ao Código Civil, Decreto-lei 4.657/42(2), em vigor, o art. $3^{\circ}$ estipula que "ninguém se escusa de cumprir a lei, alegando que não a conhece". Essa Lei regulamentou a vigência, validade, eficácia, aplicação e interpretação das normas de direito brasileiras. Nesse sentido, é indesculpável desconhecer as leis e isto não exime o cidadão de cumpri-las rigorosamente. 
Esse dispositivo encontra-se ratificado no Código Penal ${ }^{(3)}$ que estabelece que "o desconhecimento da lei é inescusável. O erro sobre a ilicitude do fato, se inevitável, isenta de pena; se evitável, poderá diminuí-la de um sexto a um terço".

O erro é considerado evitável se o indivíduo, ao praticar o ato ilícito ou se omitir diante de um dever, o fizer sem consciência ou conhecimento de sua ilicitude, quando na verdade "Ihe era possível, nas circunstâncias, ter essa consciência". Quando totalmente inevitável ter conhecimento da ilicitude do fato, não existe crime e nem penalidade. Esse princípio da indesculpabilidade na legislação não tem a mesma vitalidade, porque a comunicação se processa hoje de maneira mais ágil e porque as novas gerações dispõem de mais recursos e possibilidades para tomarem conhecimento dos fatos.

O terceiro motivo é que esse deve estimular a participação dos profissionais no desenvolvimento da profissão, pois conhecendo melhor as debilidades da lei de exercício profissional podem atuar para modificá-la, aperfeiçoá-la e adequá-la à realidade social.

Por conseguinte, o parâmetro estabelecido nas normas legais do país oferece proteção não só aos que exercem determinada atividade profissional, mas também às pessoas a quem essa atividade é dirigida.

\section{Antecedentes históricos da legislação}

A legislação específica brasileira para a enfermagem ocorreu somente no alvorecer da República, com o Decreto 791/1890(4), criando a Escola Profissional de Enfermeiros e Enfermeiras (atualmente Escola de Enfermagem Alfredo Pinto).

Em 1922, foi aprovado o regulamento do Hospital Geral do Departamento Nacional de Saúde Pública, que mencionava que anexo ao Hospital, seria criada a Escola de Enfermeiras. Somente em 1923, o Decreto 16.300/23(5), ao aprovar o regulamento desse Departamento e a fiscalização do exercício profissional de médicos, farmacêuticos, dentistas, enfermeiros e parteiras, criou também uma escola para enfermeiras, atual Escola de Enfermagem Anna Néry, da Universidade Federal do Rio de Janeiro.

O Decreto $20.109 / 31^{(6)}$, apesar de referir em sua ementa "regular o exercício da enfermagem no Brasil e fixar as condições para equiparação das escolas de enfermagem" na verdade, apenas no artigo $1^{\circ}$ tratava do exercício da enfermagem, estipulando que o titulo de enfermeiro diplomado, ou suas iniciais correspondentes, só poderia ser usado se o profissional fosse diplomado por escola oficial ou equiparada na forma da lei. Os demais artigos eram relacionados ao ensino da enfermagem.

Posteriormente, o Decreto $20.931 / 32^{(7)}$, ao dispor sobre a regulamentação e fiscalização do exercício da medicina, odontologia e medicina veterinária, regulava também as profissões do farmacêutico, da parteira e da enfermeira. No tocante à enfermagem, não havia preocupação em definir a função do profissional, mas era-lhe proibido instalar consultório para atendimento de cliente.
A Lei $775 / 49^{(8)}$, dispunha sobre o ensino de enfermagem no país, mas incluiu um preceito referente ao exercício profissional no art. 21, dispondo que "as instituições hospitalares, públicas ou privadas, decorridos sete anos após a publicação desta lei, não poderiam contratar, para a direção dos seus serviços de enfermagem, senão enfermeiros diplomados". Esse artigo foi de valia, pois a Lei 775/49 nunca chegou a ser revogada, e décadas mais tarde, líderes da enfermagem usavam esse preceito legal.

Somente na década de 1950 houve a aprovação de uma lei específica que tratava efetivamente do exercício da Enfermagem. Foi a Lei $2.604 / 55^{(9)}$, que definiu as categorias que poderiam exercer a enfermagem no país e revogou dispositivos que tratavam de categorias que seriam posteriormente extintas, mas existiram por muito tempo como grupos residuais da enfermagem. Eram os enfermeiros práticos, os práticos de enfermagem, enfermeiro militar e atendentes, entre outras inúmeras denominações.

Antes da Lei 2604/55 ser regulamentada, o Congresso Nacional aprovou a Lei 3.780/60 ${ }^{(10)}$, que dispunha sobre a Classificação de Cargos do Serviço Civil do Poder Executivo, que teve influência na enfermagem. As diversas denominações existentes à época, na enfermagem, foram reduzidas de acordo com as regras de enquadramento por similaridade de atribuições e responsabilidades. Apesar de não tratar especificamente da enfermagem, essa lei causou impacto na profissão, pois o enfermeiro foi enquadrado como profissional técnico-científico de nível superior no serviço público federal. Ela abriu caminho para que nos âmbitos estadual e municipal fosse o enfermeiro também reconhecido como categoria de nível universitário com remuneração correspondente.

Finalmente, o Decreto 50.387/61 ${ }^{(11)}$ regulamentou o exercício da enfermagem. Houve tentativa de definição do exercício da enfermagem, porém restrito à observação e cuidado de doente, gestante e acidentado; administração de medicamentos e tratamentos prescritos pelo médico; educação sanitária e aplicação de medidas de prevenção de doenças. Definiu todas as categorias que poderiam exercer legalmente a profissão, inclusive obstetras e parteiras. Havia, porém, indefinição de funções de enfermagem entre as categorias existentes. Como o técnico de enfermagem não existia na época da aprovação dessa legislação, essa categoria ficou sem função legal até ser incluída na legislação posterior.

A Lei $5.905 / 73^{(12)}$, criou os Conselhos Federal e Regionais de Enfermagem e definiu sua competência como órgãos disciplinadores do exercício da enfermagem. Para disciplinar o exercício, os Conselhos precisariam contar com uma lei própria que englobasse todas as categorias profissionais.

O primeiro Conselho Federal de Enfermagem, constituído por nove membros, foi nomeado pelo Ministro do Trabalho, Arnaldo Prieto, em abril de 1975, a partir de uma lista tríplice encaminhada pela Associação Brasileira de Enfermagem. A primeira Diretoria teve Maria Rosa Sousa Pinheiro como presidente, eleita pelos pares. Uma das providências dessa diretoria foi a elaboração 
de um código de ética e de um anteprojeto da lei do exercício profissional. Instalou administrativamente o COFEN; aprovou um regimento interno; e, instalou os CORENs em 22 Estados da Federação, com eleição e posse dos seus presidentes.

A Lei 7.498/86 (13), foi regulamentada pelo Decreto n. 94.406/87, e ambos constituem os atuais dispositivos legais do exercício profissional da enfermagem, vindo a substituir a Lei $2.604 / 55$ e o Decreto $50.387 / 61$. Na nova lei não houve redefinição do que seria a enfermagem, mas estabeleceu competências privativas do enfermeiro, inclusive no tocante à consulta e à prescrição da assistência de enfermagem e aos cuidados de enfermagem de maior complexidade técnica, inexistentes nas normas anteriores. Foram também incluídas as atribuições dos técnicos e auxiliares de enfermagem, sempre sob orientação e supervisão do enfermeiro.

\section{Legislação atual}

A atual Constituição consolidou algumas conquistas no campo do direito de família como o reconhecimento e proteção à união estável, a igualdade absoluta de direitos do homem e da mulher, a equiparação da filiação para todos os efeitos, o novo sentido social da propriedade, novas modalidades de usucapião, dentre outros tópicos importantes.

A Lei $10.406 / 2002^{(14)}$ instituiu o Código Civil, revogou o anterior, de 01-01-1916, e entrou em vigor no dia 11 de janeiro de 2003. A questão da idade do Código não é relevante, pois há códigos mais antigos e que continuam em vigor como o da França, que é de 1804 e da Alemanha, de 1900. Na Espanha, o texto mudou porque o anterior havia sido idealizado pelo ditador Francisco Franco, assim como o de Portugal, por Antonio Salazar. Já o Código Civil Brasileiro não havia sido produzido por ditadores, mas por juristas como Clovis Bevilaqua e Rui Barbosa.

O novo Código Civil (CC) contou com outro jurista de porte, o Professor Miguel Reale, incumbido da tarefa de elaborar o projeto em 1969, pelo Presidente da República, General Costa e Silva. Foi mantida a estrutura do código de 1916, e acrescentada uma parte nova sobre o Direito de Empresa, que estava obsoleta no Código Comercial de 1850. Outras leis foram incorporadas, com algumas modificações, no Código Civil, como é o caso da Lei 4.591/64 sobre o condomínio em geral, como parte do Direito das Coisas, que inclui o direito de propriedade. Embora o Anteprojeto tivesse sido apresentado em 1973, em 1984 foi publicado como projeto pela Câmara dos Deputados. A história política do país não permitiu que esse projeto fosse devidamente analisado, na época. Nesse meio-tempo, houve a aprovação da Constituição Federal de 1988, assim como do Código de Defesa do Consumidor ${ }^{(15)}$ e o Estatuto da Criança e do Adolescente $e^{(16)}$.

A Constituição teria impacto no exercício da enfermagem? E o Código Civil? Em que e como a Constituição, os Códigos Civil ou Penal poderiam influir nas relações profissionais ou na atuação da enfermagem?

Entre os direitos da personalidade, definidos no CC como intransmissíveis e irrenunciáveis (art. 11), podem ser citados o art.14, sobre "a disposição gratuita do próprio corpo, no todo ou em parte, para depois da morte, com objetivo científico e altruístico", nesse caso, para fins de transplante, mas "ninguém pode ser constrangido a submeter-se, com risco de vida, a tratamento médico ou a intervenção cirúrgica", conforme o art. 15.

A Constituição Brasileira, de 1988, assegura a todos o direito à saúde, sob responsabilidade do Estado (art.196), mediante políticas sociais e econômicas que visem à redução do risco de doenças e de outros agravos assim como o acesso universal e igualitário aos serviços que visem à promoção, proteção e recuperação da saúde. Dá prioridade às ações e serviços públicos de saúde integrantes do Sistema Único de Saúde, e admite que a iniciativa privada também possa oferecer serviços de assistência à saúde.

A Constituição afirma que "é livre o exercício de qualquer trabalho, ofício ou profissão, atendidas as qualificações profissionais que a lei estabelecer" (art. $5^{\circ}$, item XIII).

A Lei das Contravenções Penais ${ }^{(17)}$ prevê que exercer profissão ou atividade econômica, ou anunciar que a exerce, sem preencher as condições a que por lei está subordinado o seu exercício "constitui uma contravenção penal (infração menor que o crime) sujeita à pena de prisão simples ou multa".

O elemento moral das contravenções é a voluntariedade da ação ou omissão, istoé, para o reconhecimento de fato contravencional, prescinde-se do dolo (intenção) ou da culpa. Qualquer destas formas de culpabilidade é tomada em consideração quando de sua existência depende algum efeito jurídico, por exemplo qualquer delas condicione, excepcionalmente, a própria existência da contravenção, ou se trate de graduar ou individualizar a pena aplicável no caso concreto. As penas principais são prisão simples (executada sem rigor penitenciário e não podendo exceder, a cinco anos) e a multa que é conversível em prisão simples nos mesmos casos excepcionais em que o Código Penal admite sua conversão em detenção.

O Código Penal(3), estabelece que "o desconhecimento da lei é inescusável. O erro sobre a ilicitude do fato, se inevitável, isenta de pena; se evitável, poderá diminuí-la de um sexto a um terço".

Que qualificações ou condições seriam aquelas? Não se trata evidentemente de uma qualificação, capacidade ou aptidão física ou mental enem mesmo técnica, mas de capacidade legal.Obviamente, capacidade legal supõe capacidade técnica e profissional, mas só esta é insuficiente para o exercício legal da profissão. É o que ocorre com as pessoas formadas em outros países, que, para trabalharem em nosso país, necessitam revalidar ou registrar seus títulos. Pode ocorrer também com qualquer pessoa que, estando formada, não registra seu titulo em órgão disciplinador do exercício.

É necessário lembrar também que o Código de Proteção e Defesa do Consumidor ${ }^{(15)}$ estabelece regras para o relacionamento entre consumidores e fornecedores ou prestadores de serviços e para a proteção e defesa dos consumidores, como parte dos direitos da cidadania. Consumidor é toda pessoa física ou jurídica que adquire 
ou utiliza qualquer produto ou serviço como destinatário final; e fornecedor ou prestador de serviço é pessoa física ou jurídica, pública ou privada, nacional ou estrangeira que desenvolve atividades de produção, montagem, criação, construção, transformação, distribuição e comercialização de produtos ou serviços. Entre os direitos básicos do consumidor, incluem-se a proteção da vida, saúde e segurança contra riscos provocados por produtos ou serviços considerados perigosos ou nocivos. Assim, o profissional de enfermagem seria o fornecedor ou prestador do serviço e o cliente/ paciente o consumidor desse serviço. Um dos mais importantes direitos do consumidor, criado a partir desse Código, foi "a facilitação da defesa de seus direitos, inclusive com a inversão do ônus da prova, a seu favor, no processo civil, quando verossímil a alegação". A inversão do ônus da prova foi realmente uma inovação que veio beneficiar consumidores em geral, mas na área da saúde adquiriu significado especial. Em direito, afirma-se que "quem alega deve provar", isto é, o ônus de fazer a prova recai sempre sobre quem alega ou faz uma acusação. Na área da saúde, o paciente que se sentisse prejudicado ou mal assistido deveria provar essa afirmação contra o profissional. Era uma missão quase impossível a um leigo fazer prova contra um profissional, sem mencionar o corporativismo que existia entre os profissionais, protegendose mutuamente. Esse Código veio exatamente inverter essa ordem, pois agora é ele, o profissional, que deve provar que a assistência prestada era a indicada, correta e de qualidade. Portanto, com base nesse Código, é o acusado (profissional ou empresa, hospital) que deve provar que agiu corretamente e de acordo com as normas técnicas recomendadas, desonerando o acusador (paciente ou consumidor) de juntar provas para sua alegação.

\section{Legislação profissional de enfermagem}

A liberdade de exercer a profissão ou atividade, assegurada pela Constituição, está limitada pelas condições de qualificação profissional que a lei estabelecer. No caso da enfermagem, qual seria essa lei?

Conforme referido, a Lei $7.498 / 86^{(13)}$, que trata do exercício profissional da enfermagem dispõe em seu art. $1^{\circ}$ que "é livre o exercício da enfermagem em todo o território nacional, observadas as disposições desta Lei".

O Decreto $94.406 / 87^{(18)}$ especifica que"o exercício da atividade de enfermagem, observadas as disposições da Lei 7498/86, e respeitados os graus de habilitação, é privativo do enfermeiro, técnico de enfermagem, auxiliar de enfermagem e parteiro e só será permitido ao profissional inscrito no Conselho Regional de Enfermagem da respectiva região". Além de definir quem é cada um dos profissionais antes mencionados o Decreto 94.406/87, descreve as atribuições para cada uma dessas categorias do pessoal de enfermagem. Para o enfermeiro são descritas as atividades privativas e as que deve realizar como integrante de equipe de saúde. Portanto, aquele que não possui um desses títulos também não pode exercer a enfermagem.
Em virtude da carência de recursos humanos de nível médio nessa área, a Lei 7.498/86, no art. 23, permitiu que o pessoal sem formação específica, tais como os atendentes de enfermagem e agentes de saúde que se encontravam executando tarefas de enfermagem, continuasse nessa atividade desde que autorizado pelo COFEN.

Embora não existisse mais prazo legal que obrigasse esse pessoal a buscar formação especifica, o Ministério da Saúde, preocupado com o problema, instituiu projeto de alcance social, o PROFAE - Projeto de Profissionalização dos Trabalhadores da área de Enfermagem, levado a efeito com recursos de várias entidades nacionais e internacionais, que profissionalizou esses trabalhadores, atendentes de enfermagem e agentes de saúde, uma população estimada em mais de 200.000 pessoas, a fim de melhorar a qualidade dos serviços de saúde. Segundo Gottems $^{(19)}$, em 1983, 65\% da força de trabalho de enfermagem era constituída por pessoal sem qualificação técnica formal, e em 1998 esse percentual passou a 35\%, o que demonstra o impacto nos serviços dessa profissionalização.

A titularidade constitui condição de capacidade técnica para o exercício profissional em qualquer profissão. Daí a importância que a lei confere à qualificação ou ao título profissional de acordo com o grau de preparo e formação. Por isso, na divisão do trabalho de enfermagem, as atividades mais complexas e de maior responsabilidade são atribuídas aos enfermeiros, profissionais de maior preparo acadêmico.

O Decreto n. 94.406/87 é claro quanto às atividades privativas de direção e liderança do enfermeiro, exercidas nos órgãos de enfermagem, públicos ou privados. Cabe ainda ao enfermeiro em caráter privativo a consulta e prescrição da assistência de enfermagem, assim como os cuidados diretos de enfermagem a pacientes graves com risco de vida e os de maior complexidade técnica e que exijam conhecimentos científicos adequados e capacidade de tomar decisões imediatas.

Como integrante de equipe de saúde, o enfermeiro tem no art. $8^{\circ}$, um elenco de 17 atividades, onde ele participa na elaboração, no planejamento, execução e avaliação de planos e programas de saúde, de treinamento de pessoal de saúde, assim como na prestação de assistência obstétrica e execução de parto sem distócia, em situação de emergência, entre outras funções.

Os profissionais portadores do titulo de obstetra, enfermeira obstétrica (art. $9^{\circ}$ ) ou enfermeiro obstetra, além das atividades já mencionadas, podem também prestar assistência obstétrica à parturiente e ao parto normal, assim como identificar distócias obstétricas e tomar providências até a chegada do médico; e realizar episiotomias e episiorrafias, com aplicação de anestesia local. O parteiro ou parteira pode prestar assistência à gestante e à parturiente, assistir ao parto normal, inclusive em domicílio e cuidar da puérpera e do recémnascido. Essas atividades devem ser exercidas sob supervisão de enfermeira obstétrica, quando realizadas em instituições 
de saúde e, sempre que possível, sob controle e supervisão de unidades de saúde, quando realizadas em domicílio.

As funções dos técnicos de enfermagem e dos auxiliares de enfermagem também estão descritas no mesmo Decreto, cabendo-Ihes atividades auxiliares de nível médio técnico, inclusive as de assistência de enfermagem, excetuadas as privativas do enfermeiro e as específicas de assistência obstétrica.

\section{Considerações finais}

Como se vê, enfermeiros e profissionais de enfermagem têm espaço para lutar pelo reconhecimento da sua capacidade e potencialidade profissionais. Entretanto, a sociedade nãolhes dará esse reconhecimento como dádiva. Ele deverá ser conquistado com envolvimento das novas gerações de enfermeiros, não apenas como bons profissionais de ensino, de assistência ou de pesquisa, mas também no campo sócio-político, a começar pelos órgãos de classe, e daí, ascendendo para posições no legislativo e no executivo, seja no âmbito municipal, estadual ou federal.

Há exemplos, no passado, de enfermeiros como Samora Machel que, tendo sido militante enfermeiro, passou a lutar pela independência de seu país e terminou vitorioso em 1975, quando se tornou o primeiro presidente da República de Moçambique. Na Angola, três enfermeiros já ocuparam cargo de Ministro da Saúde. Na Europa, Ásia e Caribe há exemplos de enfermeiros que ocuparam esse cargo nas décadas de 1980 e 1990, inclusive na atual.

É necessário que os atuais líderes da profissão comecem a semear o terreno, descobrindo futuros líderes e preparando-os para assumirem posições na sociedade, traçando as metas e elaborando as estratégias que possibilitem alcançá-las. Só assim seria possível deixar para as novas gerações uma enfermagem mais abrangente, respeitada e profissionalmente valorizada.

\section{Referências}

1. Constituição da República Federativa do Brasil. Promulgada em 05-10-1988.

In: Gomes LF. Código Penal, Código de Processo Penal, Constituição Federal.

São Paulo: Revista dos Tribunais; 2000.

2. Decreto-lei 4657, de 04/09/1942 - Lei de Introdução ao Código Civil (LICC).

Diário Oficial da União. Rio de Janeiro, 09/09/1942.

3. Decreto-lei 2.848, de 07-12-1940, de acordo com a reforma da Lei 7.209,

de 11-07-1984. In: Delmanto C. Código Penal comentado. $5^{\mathrm{a}} \mathrm{ed}$.

Rio de Janeiro: Renovar; 2000. p. 3-650.

4. Decreto 791, de 27-09-1890. Cria no Hospício Nacional de Alienados uma

escola profissional de enfermeiros e enfermeiras. In: Ministério da Saúde.

Fundação Serviços de Saúde Pública. Enfermagem, legislação e assuntos

correlatos. $3^{\text {a }}$ ed. Rio de Janeiro: [s...]; 1974. p. 26-7.

5. Decreto 16.300, de 31-12-1923. Aprova o regulamento do Departamento

Nacional de Saúde Pública. In: Ministério da Saúde. Fundação Serviços

de Saúde Pública. Enfermagem, legislação e assuntos correlatos. $3^{a}$ ed.

Rio de Janeiro: [s.l.]; 1974. p. 57-66.

6. Decreto 20.109, de 15-06-1931. Regula o exercício da enfermagem

no Brasil e fixa as condições para a equiparação das escolas de enfermagem e instruções relativas ao processo de exame para revalidação de diplomas. In: Ministério da Saúde. Fundação Serviços de Saúde Pública. Enfermagem, legislação e assuntos correlatos. 3a ed. Rio de Janeiro: [s.I.]; 1974. p. 68-72. 7. Decreto 20.931, de 11-01-1932. Regula e fiscaliza o exercício da medicina, da odontologia, da medicina veterinária e das profissōes de farmacêutico, parteira e enfermeira no Brasil e estabelece penas. In: Ministério da Saúde. Fundação Serviços de Saúde Pública. Enfermagem, legislação e assuntos correlatos. $3^{\text {a }}$ ed. Rio de Janeiro: [s.l]; 1974. p. 75-82.

8. Lei 775, de 6 de agosto de 1949. Dispõe sobre o ensino de enfermagem no País e dá outras providências. In: Ministério da Saúde.

Fundação Serviços de Saúde Pública. Enfermagem, legislação e assuntos correlatos. $3^{\text {a }}$ ed. Rio de Janeiro: [s.I.]; 1974. p. 154-7.

9. Lei 2.604, de 17-09-1955. Regula o exercício da enfermagem profissional. In: Ministério da Saúde, Fundação Serviços de Saúde Pública. Enfermagem legislação e assuntos correlatos. $3^{a}$ ed. Rio de Janeiro: [s.I.]; 1974. p. 177-9.

10. Lei 3.780, de 12-07-1960. Dispöe sobre a Classificação de Cargos do Serviço
Público Civil do Poder Executivo, estabelece os vencimentos correspondentes e dá outras providências. In: Ministério da Saúde, Fundação Serviços de Saúde Pública. Enfermagem - legislação e assuntos correlatos. $3^{\mathrm{a}}$ ed. Rio de Janeiro: [s.I.]; 1974. p. 188-209.

11. Decreto 50.387, de 28-03-61. Regulamenta o exercício da enfermagem e suas funçōes auxiliares no território nacional. In: Ministério da Saúde, Fundação Serviços de Saúde Pública, Enfermagem, legislação e assuntos correlatos. $3^{\text {a }}$ ed. Rio de Janeiro: [s.l.]; 1974. p. 217-22.

12. Lei 5.905 , de $12-07-1973$, dispõe sobre a criação dos Conselhos Federal e Regionais de Enfermagem e dá outras providências. In: Conselho Regional de Enfermagem de São Paulo. Documentos básicos de enfermagem: enfermeiros, técnicos e auxiliares. São Paulo: COREN-SP; 2001. p. 19-25.

13. Lei 7.498, de 25-06-1986. Dispõe sobre a regulamentação do exercício da enfermagem e dá outras providências. In: Conselho Regional de Enfermagem de São Paulo. Documentos básicos de enfermagem: enfermeiros, técnicos e auxiliares. São Paulo: COREN-SP; 2001. p.36-41.

14. Lei 10.406, de 10 de janeiro de 2002. Institui o Código Civil. São Paulo: Saraiva; 2002

15. Lei 8078 , de 11 de setembro de 1990, dispõe sobre a proteção e defesa do consumidor e dá outras providências. In: Negrão T, Gouveia JRF. Código Civil e Legislação Civil em vigor. 23a ed. [atualizada até 10-01-2004]. São Paulo: Saraiva; 2004. p. 586-626.

16. Lei 8.069, de 13-07-1990. Dispõe sobre o Estatuto da Criança e do Adolescente e dá outras providências. In: Negrão T, Gouveia, JRF. Código Civil e Legislação em vigor. 23ª ed. [atualizada até 10-01-2004]. São Paulo: Saraiva; 2004. p. 711-78.

17. Decreto-lei 3688, de 03-10-1941, Lei das contravenções penais.

In: Novo Código Penal. 23a ed. São Paulo: Saraiva; 1985.

18. Decreto 94.406 , de 8 de junho de 1987. Regulamenta Lei n. 7498/86

que dispõe sobre o exercício da enfermagem e dá outras providências.

Diário Oficial. Brasília, 09-06-1987. Seção 1, p. 1, fls 8853-5.

19. Gottems L. Pesquisa revela impacto do PROFAE nos serviços

de saúde (editorial). Projeto de Profissionalização dos Trabalhadores da Área de Enfermagem. Rev Form. 2003;3(7):3-4. 